\title{
Chapter 3 \\ Reconnecting Engineering \\ with the Social and Political Sphere
}

\author{
Jameson M. Wetmore
}

Many students choose to study engineering because they want to make the world a better place. They have skills in math and the sciences and they want to use those skills to create technologies that solve problems. They want to make people's lives easier and they want to find answers to society's most pressing dilemmas. The promise that engineering can address many of the world's "Grand Challenges" gives them a sense of direction and purpose.

All too often, however, as students progress through their undergraduate programs, this vision and purpose get clouded. A recent study has argued that engineering programs foster a "culture of disengagement" and that the public welfare concerns of students enrolled in them decrease over time (Cech 2014). There are likely many factors for this. The focus of the first two years of most engineering programs is on math and science courses and these are rarely linked to engineering practice, let alone social needs. Ethics courses are rare, and when they are taught they typically focus on microethics - local responsibilities - rather than the broader social questions covered in macroethics (Herkert 2005). And even design courses, which are supposed to help students think independently and connect different sets of expertise, rarely include significant attention to the social and political aspects of the problems being addressed. Students often enter engineering programs with broad social goals, but as they navigate through the details of a technical education their perspective and aspirations can narrow significantly.

I frequently see this firsthand when I teach engineering undergraduates. I usually find that the ethical dilemmas that are typically presented to engineering students distract them from the most important ethical questions. But occasionally I will ask them one. For instance, I have asked groups of students what they would do if their boss asked them to design a technology that they knew would put hundreds of people

J. M. Wetmore ( $\square)$

School for the Future of Innovation in Society, Arizona State University,

Tempe, AZ, USA

e-mail: Jameson.Wetmore@asu.edu

(C) The Author(s) 2018

E. Subrahmanian et al. (eds.), Engineering a Better Future,

https://doi.org/10.1007/978-3-319-91134-2_3 
out of work or whether they would design a deadly explosive device that could be concealed in a working mobile phone. Usually, the vast majority of students agree that they would. When I ask them why they offer two justifications: 1. "It's my job." and 2. "If I don't do it someone else will." Once when I was faced with a room full of young, bright, and talented budding engineers in their fourth year of undergrad making these arguments I tried to insult them to get them to see the implications of what they were saying: "Do you all simply think you are cogs in the wheel? Are there no ethics in your work? Are you simply mindless drones that do what you are told?" To my great sadness, most of them simply nodded "yes." By the time of graduation, many of these students had abandoned their hopes of changing the world and decided that their role in life was to solve the small technical problems that are assigned to them.

Technology is widely acknowledged to be at least part of the solution to many of the world's complex problems. The trick is that technologies have to be woven into society carefully and there must be accompanying social and political changes that complement them if real progress is to be achieved. Engineers will be needed to make this happen. At least one prominent sociologist has even noted that the most accomplished engineers are quite good at weaving the social, political, and technological together. Michel Callon contends that engineers "construct hypotheses and forms of argument that pull these participants into the field of sociological analysis. Whether they want to or not, they are transformed into sociologists, or what I call engineer-sociologists" (Callon 1987, p. 84). If technologies are going to be part of the solutions society needs, the "cogs in the wheel" we train must transition into "engineer-sociologists." Those with narrow technical expertise will need to develop a broader perspective to solve social challenges.

Thankfully, despite the culture of disengagement in many undergraduate programs, there are students who hold out hope that they can make a difference. They comply when they are told to focus on ever smaller technical details. But secretly they aspire to do something bigger and look for outlets for their interest.

For the past decade, I have been working to create opportunities for engineers such as these. Below I briefly outline two of them. These programs are designed to reconnect these engineers with the social and political contexts they work in and which they would like to improve.

\subsection{Science Outside the Lab}

The first of these interventions is Science Outside the Lab (SOtL), a program developed by the Consortium for Science, Policy \& Outcomes (CSPO) to introduce graduate student scientists and engineers to the policy process (http://cspo.org/ program/science-outside-the-lab/). SOtL is typically held in Washington, DC and brings together approximately 14 science and engineering doctoral students. Over the course of one or two weeks, the students meet dozens of people who work at the interface of engineering, policy, and society including policymakers, regulators, funders, lobbyists, lawyers, and museum professionals (Bernstein et al. 2016). 
Most of the students that participate in the program start with the belief that policymakers in Washington, DC are either ignorant, corrupt, or a combination of the two. The program introduces them to incredibly intelligent policymakers, many of whom have science backgrounds, who have the difficult job of juggling the variety of values and pressures that go into making decisions that impact thousands if not millions of lives. Both anecdotal evidence and detailed evaluations have shown that the program goes a long way toward helping students understand the importance of the social context of engineering.

Students find that science and engineering knowledge is an important part of policymaking, but that it cannot dictate what should be done. The knowledge is only useful when combined with a robust understanding of the social and political factors and implications at play. By both understanding and recognizing the inherent worth of the values of different people and organizations, students learn how to play a more productive role in the policy process. As their respect for policy rises, they lessen their criticisms of it. And as they learn the place of engineering in the process, they are better able to do work that can directly inform policy.

The program was designed to help students become more effective at their jobs as scientists and engineers. And there is evidence that it has done that. Some participants, for instance, have reworked their dissertation research to inform deliberations over regulation that they learned about in the program and their findings were later cited in Federal rulemakings. Over time, however, students have used the program as a springboard to nontechnical jobs. Several graduates have gone on to take up positions in state and federal governments. By opening their eyes up to the complexities of policy, many students are drawn to crucially important problems that their technical tools cannot solve. Through this process, they slowly become a bridge by which different sets of expertise can be brought together.

\subsection{Community Engagement Workshops}

The second intervention is a response to the recent trend in engineering undergrad programs to offer some sort of experience whereby the students get a design challenge to solve a problem faced by people in the developing world. Unfortunately, many of these programs remain focused on technical details and the resulting designs offer little to no help to the local people who were supposed to benefit. It takes an especially talented "engineer-sociologist" to understand the nuances of a foreign culture, community, and place.

In an effort to address this problem and better prepare students to engage with communities, the "Equity, Equality, and Responsibility" subgroup of the Center for Nanotechnology in Society at ASU developed a two day "Community Engagement Workshop" that has been held five times in the US, Canada, and South Africa (Harsh et al. 2017). The major goal of the workshop is to give the participants an appreciation for the social complexities inherent in transferring technologies to developing areas and to imbue them with a sense of humility. 
There are three major learning goals: 1 . Decenter Technology. The students are shown the number of ways that a focus on specific technological artifacts can lead to enormous failures in development efforts and are encouraged to consider technologies as a possible component of a solution rather than the focus of a solution. 2 . Listen to and learn from communities. The majority of development efforts fail because the outsider seeks to address a problem that the local people do not see as a problem. The course introduces students to ways to listen to a local community to better understand the community's concerns rather than making assumptions from the outside. And 3. Empower Communities. Many development projects work fine when the outsiders are still in the area, but as soon as they leave the programs fall into disrepair. One major step that can be taken to change this is to empower the local people to play a role in the project from the very beginning.

These workshops do not fully prepare students to have successful interventions in the developing world. Such a training program would take weeks, if not years. Rather, the exercises are designed to help the students begin to see the complexities involved in integrating any technology into the practices and institutions of a group of people. This brief introduction allows students to make a more informed decision as to whether they want to dedicate the time and effort necessary to make a direct positive impact in developing areas.

\subsection{Conclusion}

Not every student who participates in these programs will become proficient "engineer-sociologists." That is not a problem, however, because ultimately that is not the goal. We do not portend to teach the engineers involved everything they need to know about technology and society.

The graduates of these programs are, however, changed in two fundamental ways: First, often once they get an introduction to these ideas they want to know more and they seek to continue their education. They go on to study those issues that are most important in their field or for themselves personally. These programs often rekindle interests that have long lay dormant in thoughtful individuals and help them to find ways to reintegrate them into their lives and practice. Second, students come to better realize what they don't know. This acknowledgment of a deficit frequently leads them to better understand the importance of consulting other forms of expertise. An engineer who knows how to bring together the different experts necessary to solve important problems can be as beneficial as a lone "engineer-sociologist." Sometimes bridges are best made out of a chain of many people working together.

These interventions demonstrate that it is possible to break students out of the "culture of disengagement" that seems to be present in many engineering programs. Many of the students drawn to them knew that there was something missing in their education, but couldn't quite put their finger on it. We have seen the scales fall from the eyes of many of them. The experience often reinvigorates the students and they themselves are empowered to play key roles in productive change. There are ways to turn "cogs in the wheel" into leaders and bridge builders. 


\section{References}

Bernstein, M. J., Reifschneider, K., Bennett, I., Wetmore, J. M. (2016). Science outside the lab: Helping graduate students in science and engineering understand the complexities of science policy. Science and Engineering Ethics, posted online 28 September.

Cech, Erin A. (2014). Culture of disengagement in engineering education? Science, Technology and Human Values, 39(1), 42-72.

Callon, M. (1987). Society in the making: The study of technology as a tool for sociological analysis. The social Construction of Technological Systems: New Directions in the Sociology and History of Technology, 83-103.

Harsh, M., Bernstein, M. J., Wetmore, J., Cozzens, S., Woodson, T., Castillo, R. (2017). Preparing engineers for the challenges of community engagement. European Journal of Engineering Education, 42(6), 1154-1173.

Herkert, J. R. (2005). Ways of thinking about and teaching ethical problem solving: Microethics and macroethics in engineering. Science and Engineering Ethics, 11(3), 373-385.

Jameson M. Wetmore is an Associate Professor in the School for the Future of Innovation in Society and Co-Director of the Center for Engagement \& Training in Science \& Society at Arizona State University. His work combines the fields of science and technology studies, ethics, and public policy to better understand both the interconnected relationships between technology and society and the forces that change those relationships over time. His recent work has been largely focused on two audiences. He works closely with scientists and engineers, often as part of the National Nanotechnology Coordinated Infrastructure, to build an understanding of the context of their research to increase their effectiveness in developing useful knowledge and technologies. And as part of the National Informal STEM Education Network, he collaborates with science center professionals across the country to help them embed discussions about the social aspects of present and future technologies on the museum floor. He is co-author of Technology and Society: Building our Sociotechnical Future (MIT Press, 2008).

Open Access This chapter is licensed under the terms of the Creative Commons Attribution 4.0 International License (http://creativecommons.org/licenses/by/4.0/), which permits use, sharing, adaptation, distribution and reproduction in any medium or format, as long as you give appropriate credit to the original author(s) and the source, provide a link to the Creative Commons license and indicate if changes were made.

The images or other third party material in this chapter are included in the chapter's Creative Commons license, unless indicated otherwise in a credit line to the material. If material is not included in the chapter's Creative Commons license and your intended use is not permitted by statutory regulation or exceeds the permitted use, you will need to obtain permission directly from the copyright holder.

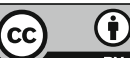

